\title{
A PSICOLOGIA E O PROGRAMA "LER E ESCREVER": A FORMAÇÃO DE PROFESSORES NA ESCOLA
}

RESUMO: O artigo traz dados de uma investigação cujo objetivo foi contribuir para a compreensão das formas por meio das quais a Psicologia vem sendo apropriada pelos projetos de formação de professores em serviço. Mediante o exame do projeto de formação do município de São Paulo, o "Programa Ler e Escrever, Prioridade na escola. Projeto Toda Força ao $1^{\circ}$ Ano", analisam-se as concepções psicológicas em suas formas de conceber as crianças, a aprendizagem e o projeto de sua iniciação na cultura escrita. A partir das reconceitualizações sobre a aprendizagem, em que esta é considerada uma decorrência da natureza construtiva da mente infantil, é pertinente perguntar em que medida essas ideias rompem com aquelas anteriores, pertencentes ao assim chamado “ensino tradicional". Para responder a essas perguntas, recorreu-se a algumas das contribuições da história da leitura.

Palavras-chave: Psicologia e Formação de Professores; Psicologia e Alfabetização.

\section{PSYCHOLOGY AND THE “READING AND WRITING" PROGRAM: TEACHING TRAINING IN SCHOOL}

ABSTRACT: The article presents data from an investigation, having as its objective, a deepening of our comprehension of how psychology is being applied in educating teachers, who are already in service. By examining the São Paulo training program "The Reading and Writing Project, Priority in school" and "The Project, All Power to the First Year", the way children are conceived of, based upon psychological concepts, is analyzed, alongside their learning achievements and initiation into our writing culture in response to projects designed to facilitate this. Because of new ways we have of conceptualizing the learning process, where learning is now considered a consequence of the constructive nature of the young mind, it is pertinent to ask, to what extent these ideas break with previous ones, those belonging to so-called "traditional teaching". To answer this question, some contributions from the history of reading, were reviewed.

Keywords: Psychology and Teacher Training; Psychology and Literacy.

* Doutora em Psicologia pela Universidade de São Paulo (USP); Professora do Departamento de Filosofia e Ciências da Educação, da Faculdade de Educação da Universidade de São Paulo (USP). E-mail: sandrasawaya@yahoo.com.br 


\section{Introdução}

É conhecido o fato de que a Psicologia tem fornecido as bases teóricas das concepções e ações pedagógicas brasileiras, tendo se tornado a área de maior influência na definição das reformas da educação básica. Inspirada nas contribuições de autores vinculados às teorias construtivistas do desenvolvimento infantil, a participação da Psicologia na educação tem sido tão intensa que ela passou a definir as propostas curriculares e as práticas pedagógicas a serem desenvolvidas nas instituições de ensino (cf. BRASIL, 1997; SÃO PAULO, 2006). Sabe-se também que as abordagens construtivistas deram origem a orientações e perspectivas educacionais bastante diversas entre si, que estão em disputa no discurso educacional no Brasil.

Alguns estudos, no entanto, ao analisar a influência das ideias do psicológico suíço Jean Piaget na educação no Brasil, têm mostrado que as próprias concepções construtivistas passaram por interpretações diversas, e até mesmo por desvirtuamentos na sua aplicação às práticas educacionais (VASCONCELOS, 1996). Estudos também têm evidenciado a série de limitações e problemas decorrentes de uma transposição acrítica de conceitos e perspectivas da Psicologia do Desenvolvimento e da Epistemologia Genética desse estudioso para a educação (CARVALHO, 2001); outros têm empreendido a crítica da apropriação neoliberal das ideias construtivistas no Brasil e seus descaminhos na educação (SILVA, 1996; DUARTE, 2000). Entretanto, pouco se conhece sobre como essas concepções foram "lidas", "apropriadas" pelos legisladores e técnicos das Secretarias da Educação responsáveis pela transformação dessas concepções em propostas e práticas pedagógicas na formação dos professores nas Horas de Trabalho Pedagógico Coletiva - HTPCs. O presente artigo tem por objetivo contribuir nesse sentido, mediante a análise do documento impresso Guia de estudo para o horário coletivo de trabalho, organizado como material de formação continuada dos professores do ensino básico nas próprias unidades escolares. O documento, elaborado pela Diretoria de Orientação Técnica (DOT) da Secretaria Municipal da Educação de São Paulo com o intuito de servir de "ferramenta de trabalho" para o coordenador pedagógico, foi lançado em 2006, como parte das ações do governo municipal em sua tentativa de "reverter o quadro de fracasso escolar associado à alfabetização” (SÃO PAULO, 2006). Integrando o 
"Programa Ler e Escrever Prioridade na Escola", do qual fazem parte os projetos "Toda Força ao 1'. Ano", "Projeto Intensivo no Ciclo I - PIC" e "Projeto Ler e Escrever em todas as áreas no Ciclo II", o Guia de estudos para o horário coletivo de trabalho é constituído por uma coletânea de mais de quinze textos destinados à leitura e ao estudo dos professores do Ensino Básico. Como mais uma das inúmeras estratégias de melhoria do ensino que se sucedem em São Paulo, a proposta, tal como se apresenta na sua introdução, é a de comprometer os professores de todas as áreas de ensino a "criar condições adequadas de aprendizagem da leitura e da escrita para todos os alunos ao final do $1^{\circ}$. Ano do Ciclo I" e, assim, "assegurar um melhor desempenho de seus alunos nas práticas de leitura e escrita, na produção de textos e compreensão do que lêem" (SÃO PAULO, 2006a, Introdução).

Passados mais de vinte anos da difusão das ideias construtivistas na educação escolar no Brasil, o documento em análise permite examinar as apropriações múltiplas e variadas das teorias psicológicas dos textos que orientam as práticas e a formação dos professores no Ensino Básico. No momento em que está em curso uma revolução na educação pública, a partir de reconceitualizações sobre a aprendizagem, ao considerá-la uma decorrência do desenvolvimento da mente infantil, em que medida essas ideias rompem com aquelas anteriores, do chamado "ensino tradicional", ou mantêm traços de continuidade? Como se articulam, no documento, as novas concepções de criança e de sua aprendizagem trazidas pelas contribuições construtivistas e as propostas pedagógicas de leitura e escrita? Para responder a essas perguntas, apoiamo-nos em algumas das contribuições da história da leitura e da cultura proposta pelo historiador francês Roger Chartier (1999).

As contribuições de Chartier (1999), cujo pensamento tem influenciado algumas produções na área de educação no contexto latinoamericano, têm mostrado a necessidade de ler os textos impressos, buscando neles a reconstrução histórica das ideias e suas apropriações. Nessa perspectiva, o impresso em análise é produto de diferentes discursos que circulam no campo da educação. Seus organizadores são, de alguma forma, porta-vozes das ideias e representações que têm configurado os projetos de educação destinados às escolas públicas brasileiras. Como texto produzido no confronto entre a proposta de normatizações e as apropriações singulares de sujeitos históricos, ele permite vislumbrar as 
dinâmicas que estão em jogo nas percepções e proposições de ensino das crianças de camadas populares na atualidade. Ou seja, buscamos compreender e analisar os significados de criança e escola que estão em litígio, e as práticas escolares propostas no projeto de formação.

\section{Uma breve retomada histórica da participação da Psicologia na configuração do campo de saberes na educação}

É sabido que as mudanças na educação no Brasil, acompanhando as reformas internacionais, têm redefinido o trabalho pedagógico, não mais por áreas de conhecimento, mas pela transformação dos conteúdos do ensino em meios para a formação do indivíduo frente aos novos desafios e demandas da sociedade globalizada (MELLO, 2004). A questão central do ensino passou a ser promoção da evolução e da adaptação dos processos cognitivos de cada aluno, com vista a seu "aprender a aprender", "aprender a ser" e "aprender a fazer". Nessa perspectiva, a ênfase na aprendizagem, considerada como uma decorrência dos processos construtivos da mente infantil, passou a demandar do professor a identificação dos estágios de desenvolvimento cognitivo de cada aluno e da sua construção individual de conhecimento como eixos centrais dos processos pedagógicos. É preciso recordar que, nesse contexto, ocorreu também o revigoramento das explicações para os problemas escolares de grande parcela do alunado como decorrentes de dificuldades de aprendizagem, devido aos diferentes estágios cognitivos e linguísticos em que os alunos de camadas populares iniciam sua escolarização (BRASIL, 1997).

Contudo, não é nova a preocupação de se identificar a diversidade no funcionamento psíquico dos alunos de camadas populares e, a partir dela, propor situações de ensino. Os historiadores da Psicologia no Brasil recordam que a educação sempre esteve preocupada com a identificação e a intervenção na heterogeneidade que caracteriza, desde o descobrimento, a nação brasileira (PATTO, 1997). Desde o século XIX, a miscigenação racial e a composição étnica e antropológica singular da sociedade de "raças cruzadas" (ROMERO, 1895 apud SCHWARCZ, 2001, p. 11), que serviu de explicação para o atraso da nação e para a tomada de medidas educacionais e médico-higienistas (GONDRA, 2002), constituíram o tema das diferenças individuais ou 
grupais em um dos objetos caros ao campo das ciências sociais e da Psicologia nascentes no país. Vale ainda lembrar que a presença da Psicologia na educação aconteceu não apenas por meio das contribuições das teorias da aprendizagem, da motivação, da percepção e da memória, mas, principalmente, por ter fornecido os meios para identificar, explicar e propor modelos de intervenção no enfrentamento das diferenças na população. $\mathrm{Na}$ busca das causas da diversidade entre os indivíduos ou grupos, a questão não se colocou como decorrência da desigualdade social inerente ao modo de produção capitalista, mas encontrou suas justificativas nas teorias das desigualdades raciais, pessoais ou culturais (PATTO, 1997, p. 29). Sem colocar em xeque a existência de igualdade de oportunidades na ordem social vigente, as teses explicativas sobre a heterogeneidade da população encontraram sustentação em ciências como a Psicologia, cuja tendência foi inicialmente atribuir a pobreza à inferioridade inata e, posteriormente, como decorrência de desencontros culturais devido à escassez, à privação ou à exclusão dos benefícios da civilização moderna.

Para Saviani (2007), essa tendência estava presente até mesmo entre os primeiros educadores e intelectuais brasileiros sinceramente comprometidos com a democratização do ensino no Brasil, na década de 1930. Seus adeptos, introdutores das ideias de Piaget no Brasil, tendo chamado a atenção para as especificidades psicológicas dos alunos, propuseram a reformulação dos métodos de ensino e das propostas pedagógicas. O lema era promover ao máximo o desenvolvimento das potencialidades de cada indivíduo e, para tanto, era preciso identificar o desenvolvimento cognitivo dos educandos no ato de aprender. De um lado, o que se propunha era a educação inspirada nas ideias biopsicológicas sobre o desenvolvimento infantil e suas aplicações no funcionamento da educação. Nela, um ensino de tendências individualistas, centradas em cada criança e em seu desenvolvimento para a organização da escola, fazia recorrência à "escola sob medida" de que falava Claparède, em que a cada um era dada a educação que lhe convém. De outro lado, uma concepção mais nítida do papel da escola como instituição social e a consciência mais viva de articular a escola com o meio da criança e de adaptá-la às condições de uma nova civilização. Essa de orientação mais social partia da comunidade para a formação do indivíduo. A infância, nessa acepção, não era apenas desenvolvimento, mas iniciação, isto é, fruto de um trabalho e até 
mesmo de uma violência à natureza da criança e do adolescente, cujas necessidades não são as do indivíduo, mas aquelas que se apresentam por meio da comunidade e da organização da escola como comunidade de vida. A outra, de tendências individualistas, tomava como ponto de partida o indivíduo para a organização da escola, a dinâmica do ensino e os métodos do trabalho escolar (AZEVEDO, 1971 apud SAVIANI, 2007, p. 213).

É sabido que esses educadores, cujos projetos visavam a uma revolução do ensino no Brasil, "perderam a disputa doutrinária para os conservadores", na década de 1930. Todavia, Saviani (2007) faz notar que essas ideias foram ocupando os espaços na burocracia educacional, infiltrando-se na administração pública e exercendo sua influência no aparato técnico das escolas, sedimentando, portanto, no plano das ações, concepções e ideias que emergiram e submergiram, inúmeras vezes, na história da educação no Brasil. A permanência de muitas das contribuições da Psicologia do período e dos debates em torno da escolarização de grande parcela da população brasileira, no pensamento e nas reformas educacionais da atualidade, indicam que a educação escolar brasileira se vê às voltas com concepções divergentes e ainda não resolvidas. Sabemos que as contradições ou limitações nas orientações pedagógicas criam dificuldades aos avanços para uma escolarização de qualidade. Ademais, as análises recentes sobre a situação do Ensino Básico no Brasil (BROCK; SCHWARTZMAN, 2005) revelam que, apesar das conquistas cada vez maiores no plano político e no plano das ações sociais promovidas pelo avanço da democracia no Brasil, os mecanismos perversos de exclusão social ainda se fazem presentes. Basta lembrar o baixo desempenho obtido pelos alunos brasileiros nas provas internacionais e a constatação da baixa qualidade da oferta formativa.

Diante desse quadro e das medidas educacionais para enfrentálo, cabe investigar a articulação, no documento impresso, das contribuições da Psicologia em material de formação de professores em serviço. 


\section{Guia de estudos para o horário coletivo de trabalho e o lugar da Psicologia}

O documento Guia de estudos para o horário coletivo de trabalho, como dispositivo de formação dos professores, é um dos lugares de constituição das transformações e normatizações pedagógicas propostas pelos órgãos públicos. Desse modo, a análise do material impresso permite relacionar as apropriações teóricas e as propostas doutrinárias produzidas no campo normativo da educação às questões pedagógicas e políticas postas no processo de formação do professor.

A pesquisa historiográfica (CERTEAU, 1982) tem nos ensinado que o trabalho de conferir inteligibilidade aos textos recolhidos na documentação e narrados no impresso é sempre um trabalho de apropriação, isto é, de recriação. Assim, a metodologia historiográfica, ao chamar a atenção para o fato de que os documentos escritos são uma forma de reunir, interpretar e construir sentidos, revela o duplo movimento que é preciso analisar: o trabalho de compilação e sistematização dos documentos já como trabalho interpretativo e sua recriação narrativa como trabalho de apropriação dos autores. Desse modo, analisar a presença da Psicologia como campo teórico na definição das práticas escolares e na formação docente, nessa perspectiva trazida pelos estudos historiográficos, colocanos diante de um duplo desafio: buscar os modos de pensar e de agir difundidos na organização do projeto de formação dos professores em serviço; e analisar como eles se constituíram em texto-documento de formação dos alunos-professores. Nesse sentido, como em qualquer material impresso, encontra-se o perfil de um leitor desejado e um protocolo de leitura que define as formas por meio das quais o texto deve ser lido (CHARTIER, 1993, p. 8). A própria estruturação interna do documento impresso, a série de recursos gráficos utilizados, bem como a sucessão dos capítulos e o uso de subtítulos já são material a ser analisado, pois todos esses recursos conduzem os cortes de leitura, dirigem as formas de pensamento e ação do leitor desejado e, por fim, buscam determinar suas formas de apropriação. 


\section{0 documento impresso dado à leitura dos professores}

Desde os primeiros documentos oficiais escritos nos anos 1980, é possível identificar a ideia de que é "preciso mudar", "revolucionar o ensino e suas práticas", tidas como obsoletas e antidemocráticas (SÃO PAULO, 1986). O documento em análise não foge à regra e dá continuidade à tradição de textos e conceitos que, inspirados nas teorias psicogenéticas do desenvolvimento da escrita nas crianças, pretende implantar práticas pedagógicas identificadas com ações mais democráticas e de inclusão social. O caminho eleito é, uma vez mais, o de que é preciso mudar as concepções de ensino-aprendizagem da leitura e da escrita e substituir certas práticas pedagógicas, qualificadas, nesses discursos, como autoritárias e seletivas, porque, entre outras razões, desconsideram as características cognitivas e linguísticas da clientela que passou a frequentar a escola com a democratização de seu acesso (BRASIL, 1997). Ação democrática e inclusão social se traduzem no documento como a formação de leitores e escritores, levando-se em consideração as "diferenças individuais" e a "dosagem do ensino" conforme as capacidades e possibilidades dos alunos (SÃO PAULO, 2006). Com esse intuito, o documento foi organizado sob a forma de uma coletânea de quarenta textos, entre excertos, entrevistas, trechos dos Parâmetros Curriculares Nacionais, listas de atividades, além de textos reescritos por uma equipe da Diretoria de Orientação Técnica da Secretaria Municipal da Educação, em São Paulo. Recorrendo à repetição de textos de ampla difusão na rede pública, a preocupação parece ter sido a de enfrentar a "resistência dos professores à mudança" (cf. MELLO, 1988).

Uma série de "estratégias de leitura" e de escrita, como se procurará demonstrar, conduz o documento a fazer frente àquele que tem sido considerado um dos maiores problemas quando se trata de explicar a ineficácia das modificações nas "práticas tradicionais de ensino". Para quebrar as resistências de um professor que é percebido como quem ainda precisa ser convencido a mudar suas práticas pedagógicas, a "aprender a conhecer, a fazer, a conviver e a ser”, o documento se organiza, seja do ponto de vista gráfico seja do textual, como mais uma das inúmeras tentativas de persuadir o professor e o coordenador pedagógico a "vestir a camisa" e a aderir, pessoalmente, ao projeto de mudança. Assim, o uso abundante de recursos gráficos, como desenhos no cabeçalho e no pé da 
página, a exposição dos temas por blocos e dos textos correspondentes parecem buscar, entre outras coisas, facilitar a leitura e a consulta imediata de informações e das atividades didáticas. Com um desenho gráfico que lembra um diário, de aspecto quase juvenil, o documento parece ter como preocupação sensibilizar o leitor e suavizar sua leitura através de um recurso paradoxal: distanciá-lo do texto acadêmico, cuja densidade textual, no trato e na exposição dos argumentos, exige empenho e dedicação do leitor. A ideia subjacente é a de que a razão do sucesso ou do fracasso das mudanças propostas depende da adesão pessoal do professor ao projeto ou, como já se disse em outros lugares, "do seu compromisso com o ensino". Assim, é preciso conquistá-lo. O discurso da responsabilização docente pela precariedade do ensino (SOUZA, 2006) se repete, com nuances mais ou menos evidentes, no uso de estratégias de convencimento e tentativas de trocar conceitos em miúdos e direcionar as ações. À semelhança de um grande diário, o impresso busca criar uma sensação de intimidade mediante o apelo à troca de experiências entre pares, à formação por aproximação e ao "faça como eu faço".

O documento é dividido em doze blocos temáticos cujo sumário explicita a proposta formativa em curso: o que é planejar, por quê, como; o que é e como aprender a ler e a escrever; o que é aprender a falar na escola; como avaliar; como organizar o espaço, o tempo e os conteúdos por projetos didáticos; e, por fim, como enfrentar temas polêmicos, tais como a heterogeneidade na sala de aula, como e quando corrigir.

Na página introdutória do "Bloco I", intitulado "Vamos começar pelo... PLANEJAMENTO!", um conjunto de textos extraídos de entrevistas e ensaios faz apelo à necessidade de planejamento e de como fazê-lo:

Vamos começar pelo... PLANEJAMENTO! (...)Planejar, planejar...Todo inicio de ano é a mesma coisa, a mesma conversa. O que ensinar? Como ensinar? Que critérios utilizar para planejar, o que considerar para o planejamento do ano, do bimestre? Como planejar sem conhecer bem os alunos? O guia de planejamento, que compõe este material, faz sugestões que pode ajudar muito e acalmar sua ansiedade (SÃO PAULO, 2006, p. 13).

Mas a estratégia utilizada - um texto de entrevista com uma professora experiente - deixa transparecer os sentidos e o caminho exemplar da leitura e das reflexões. Mais do que convidar à reflexão, a proposta é a 
de explicitar o rumo das mudanças que devem ser consideradas pelo professor-leitor, mediante a condução das perguntas e das respostas da professora entrevistada para uma "prática educativa de qualidade e de uma rotina adequada".

Rosinalva Dias, professora da escola pública, no ensino fundamental há 24 anos, vinte na $1^{\text {a }}$.série, fala sobre seu trabalho na sala de aula e nos conta um pouco da sua história profissional, na busca de uma prática educativa de qualidade e de uma rotina adequada para o trabalho pedagógico de alfabetização. PROFA: Como voce planeja o trabalho nas primeiras semanas de aula? Rosinalva: Todo inicio de ano, nos professores, ficamos ansiosos não só para conhecer nossos alunos, como também para organizar a rotina de trabalho. Alguns anos atras, isso não era muito tranquilo para mim e nem para os meus colegas, não só porque não tinhamos claro que atividades desenvolver, mas porque os objetivos não eram discutidos pela equipe escolar (...). PROFA: E quais são seus objetivos, em Língua Portuguesa, para a sua classe de $1^{\text {a }}$. Serie? Rosinalva: $\mathrm{O}$ que espero é que meus alunos cheguem alfabetizados ao final do $1^{\circ}$.ano, isto é, que saibam ler e escrever com autonomia, mesmo que cometam ainda muitos erros. Há alguns anos, venho utilizando em meu plano de trabalho os objetivos apresentados nos Parâmetros Curriculares Nacionais. E tenho contado com a parceria da coordenadora pedagógica da minha escola, que tem me ajudado a compreender o real significado desses objetivos e a expressá-los de fato no meu planejamento (...)PROFA: Você diz que hoje faz um trabalho diferente. O que provocou essa mudança? Rosinalva: Sem dúvida o conhecimento teórico que fui construindo ao longo do tempo.Eu sempre fiz os cursos que a Secretaria da Educação oferecia;(....). PROFA: Contenos: o que você e seus colegas fazem nas primeiras semanas do ano letivo? Rosinalva:(..)listamos todas as atividades que julgamos importantes para os alunos realizarem e que podem nos dar informações sobre quais são seus saberes em cada área a ser trabalhada. PROFA: E que atividades são essas que vocês listam?Rosinalva:(...). *leitura e escrita dos nomes dos alunos; *escrita de diferentes tipos de texto curto; apresentação do alfabeto (...) (SÃO PAULO, 2006, p. 15-19).

O uso de inúmeros recursos gráficos como desenhos, negrito, mudanças de letra, diferentes gêneros textuais, bem como a organização do conteúdo e dos discursos coloca-se a serviço de mais uma das inúmeras tentativas de ensinar o professor a planejar, a propor e a identificar os processos infantis de leitura e escrita. Assim, em outro texto, intitulado "Planejar é preciso", a advertência é clara no excerto selecionado: 
(...) Mas, e na escola, como é o planejamento?

Para muitos é o cumprimento de uma exigência burocrática de diretores e supervisores de ensino. Muitos professores reclamam pelo tempo que "perdem" elaborando um plano de trabalho e muitas vezes nem chegam a consultá-lo ao longo do ano. Um documento preparado com esse espirito com certeza não tem função no cotidiano, pois não atende a uma necessidade prática. E o que acaba acontecendo? De tudo um pouco.

Alguns professores dão aulas de improviso: Na hora eu resolvo o que vou trabalhar com os alunos.

Outros transformam o livro didático em plano de trabalho e dizem: é mais prático, não tenho que ficar inventando novidades.(...)

Um planejamento de verdade

Mas não podemos deixar de falar dos professores que, para elaborar seu planejamento, levam em conta:

o tipo de aluno que a escola pretende formar;

exigências colocadas pela realidade social;

(...)

Para esses professores, o planejamento é um instrumento de fato - um meio de organizar o trabalho e contribuir para o aprendizado dos alunos. Vejamos como isto acontece com Fátima, uma professora da $1^{a}$ série.

Fátima é professora há dezoito anos e, a cada ano, sente necessidade de aprimorar seu trabalho. Além disso, apesar de dar aulas em duas classes, sempre achou tempo para ler materiais que considera significativos para a sua prática e, com frequência, participa de cursos de atualização. A certa altura, achou que era preciso pensar em uma nova forma de planejar o trabalho. Compartilhou sua insatisfação com seus colegas e todos, juntos, resolveram que o plano daquele ano nao seguiria o esquema convencional.

E o que fizeram de tão diferente? Na verdade, não mudou muita coisa aparentemente; como qualquer plano, esse também incluia objetivos, conteúdos procedimentos didáticos e avaliação. Mas Fátima não estava tão preocupada com o conteudo do plano, e sim com a maneira de elaborá-lo, de forma a torná-lo útil de fato para ela e seus colegas (SÃO PAULO, 2006, p. 23-24).

Relatar os procedimentos adotados e o rol de atividades proposto foi o meio encontrado para descrever a operacionalização do planejamento: 
(...) $\mathrm{Na}$ escola em que Fátima trabalhava, os professores tiveram dois dias de reunião, antes do início das aulas, para discutir os objetivos da escola e preparar as atividades dos primeiros quinze dias de aula. Nessas duas semanas, os professores teriam a chance de conhecer seus alunos, identificar suas dificuldades e seu nível de conhecimento. Feito isso, haveria cinco dias de planejamento da série.

(...) Por fim, decidiram fazer uma lista do que achavam fundamental utilizar e produziram um relatório, com tudo o que haviam discutido. Objetivos, conteúdos, atividades e propostas de avaliação. Estava pronto um plano de ensino útil. (...) Em seguida, planejaram como distribuir o trabalho de Língua Portuguesa dentro do horário previsto. Além de especificar o gênero de texto (...), precisaram definir as atividades - ler, ouvir, escrever de memória, reescrever, criar, revisar. Ficou assim:

leitura pelos alunos - inclusive propostas para alunos ainda não alfabetizados. produção de texto (oral ou escrito) coletiva e individual.

(...) A tabela que fizeram pode servir de exemplo:

$2^{\circ}$ feira. Leitura pelo professor de textos narrativos. Leitura pelos alunos de textos poéticos. Produção de texto individual. $3^{\text {a }}$ feira Leitura pelo professor de textos poéticos etc. (...)

Sob o título "Bons resultados", o texto conclui que "organizar o trabalho a partir desses critérios foi um exercício difícil, mas os professores acreditavam no que estavam fazendo e isso garantiu o envolvimento de todos" e os bons resultados (p. 26).

Além de uma série de exemplos e relatos de práticas, listas de atividades a serem realizadas, etc., não há propriamente uma proposta curricular, mas a exposição teórica das formas de construção, a explicação dos processos mentais na aquisição dos conhecimentos e a apresentação de um rol de atividades e procedimentos educativos orientados para propiciar a convivência com as práticas de leitura e escrita e ativar processos de pensamento.

\section{A criança nos discursos e nas propostas práticas de ensino}

Na medida em que a nova concepção de aprendizagem considera a escrita como dependente do estágio evolutivo dos processos lógicos da mente infantil, tornou-se necessário o conhecimento, por parte dos professores, sobre os níveis de conceitualização do escrito de cada aluno, 
ou seja, as hipóteses de escrita. Associada a essa compreensão, o documento difunde também a ideia de que o conhecimento produzido sobre os esquemas cognitivos infantis, em cada etapa do desenvolvimento, é capaz de mapear e descrever o funcionamento mental da criança, além de definir as ações de intervenção ou ensino, e que, portanto, a promoção da aprendizagem do aluno requer a identificação e o desenvolvimento dos seus esquemas mentais. $\mathrm{O}$ excerto a seguir esclarece esse ponto:

Se o professor desenvolve sua prática tendo por referência teórica a idéia de que o conhecimento é construido pelo aluno em situações de interação, ele precisa dispor de estratégias que ajudem a compreender o que cada um de seus alunos já sabe. No caso da alfabetização, é essencial que o professor descubra o que cada aluno pensa sobre como funciona o sistema de escrita. Para isso é necessário em primeiro lugar que o professor estude (...) discuta com seus pares e construa para si mesmo o conhecimento hoje disponível sobre as hipóteses, as idéias que as crianças (...) constrõem em seu esforço para aprender a ler e a escrever. Infelizmente quando isso não acontece da forma adequada, o que vemos são equívocos que podem causar problemas. Alguns inaceitáveis, como pensar que silábicos são alunos que lêem de forma silabada.(...).Sem um conhecimento pelo menos básico da psicogênese da língua escrita não é possivel descobrir o que sabem e o que não sabem os alunos (p. 129).

Se o professor compreende a hipótese com que a criança está trabalhando, passa a ser possível problematizá-la, acirrar - atraves de informações adequadas - as contradições que vão gerar os avanços necessários para a compreensão do sistema alfabético (p. 48).

É a partir dessa compreensão que a questão das diferenças individuais e a heterogeneidade dos processos de aprendizagem das crianças ganham destaque no documento. Tornou-se indispensável, dentro do modelo teórico adotado, identificar as diferenças, mapear "o que sabem as crianças sobre o sistema escrito", para poder "dosar o ensino" (SÃO PAULO, 2006). Nele, as diferenças foram identificadas como diferenças quanto ao ritmo da aprendizagem, aos estilos cognitivos e aos níveis de conceitualização do escrito (BRASIL, 1997; SÃO PAULO, 2006).

As noções de heterogeneidade, diversidade ou diferença do alunado são historicamente polêmicas e sujeitas a muitas imprecisões que têm conduzido a preconceitos sociais e culturais. No documento, elas foram retomadas como uma das questões centrais, inclusive porque se tornaram imprescindíveis na organização das práticas de ensino. A ques- 
tão é abordada por meio de um pequeno texto intitulado "A heterogeneidade na sala de aula". Nele, a heterogeneidade dos alunos aparece sob a forma de apelo à diversidade humana, à natureza e à singularidade de cada indivíduo, que deve ser considerada na constituição das práticas pedagógicas (SÃO PAULO, 2006, p. 197). Impreciso e vago, o termo "diversidade" reflete a ambiguidade com que o conceito vem sendo comumente tratado em âmbito pedagógico (BRASIL, 1997) e que conduz, no texto, por vezes, à noção de diferença como atraso, ausência de competência esperada para o início da alfabetização ou à ideia abstrata de diferenças inerentes à natureza humana:

Vivemos em um momento na Educação em que a ordem é incluir (...). A escola regular, até então, demarcava (...) suas fronteiras, procurando colocar para dentro apenas alunos capazes de acompanhar seu curriculo, deixando de fora os que não possuíam essa competência. (...) A questão da inclusão escolar parece colocar uma lente de aumento naquilo que é próprio aos seres humanos: o fato de que nós todos somos singulares, únicos, marcados pelas nossas diferenças, e que a humanidade se faz por cada uma dessas singularidades (p. 198).

Assim, a "heterogeneidade da clientela" passou a ser diretamente associada às fases da evolução da mente infantil na compreensão dos conhecimentos escolares e considerada como indicador do desempenho escolar. No caso da aquisição da escrita, a diferença entre os alunos se traduz em diferença nas suas hipóteses de escrita, o que pode levar, no limite, aos problemas de aprendizagem e, por fim, ao fracasso escolar. O fulcro da argumentação é o mesmo de vários textos oficiais: a precária relação com o escrito, fora da escola, não permite às crianças, principalmente àquelas provenientes de meios populares, chegarem às instituições de ensino num patamar de desenvolvimento cognitivo esperado para o início das aprendizagens escolares (BRASIL, 1997; SÃO PAULO, 2006).

Como o documento esclarece, o planejamento das atividades e das intervenções deve ser proposto, portanto, em função "daquilo que as crianças já sabem", ou seja, dos níveis de conceitualização do sistema escrito em que se encontram (SÃO PAULO, 2006, p. 129). Decorre daí a necessidade de "avaliar", permanentemente, as crianças como condição para propor atividades de ensino que conduzam à evolução nos processos de aquisição das habilidades de ler e escrever. A avaliação, identificada 
como "sondagem", tem, no entanto, alcance restrito, pois não se trata de conhecer o aluno na complexidade das relações que envolve seu processo de escolarização, mas "as hipóteses que os alunos ainda não alfabetizados possuem sobre a escrita alfabética e o sistema de escrita de uma forma geral" (SAO PAULO, 2006a, p. 35). Não se trata de conhecer as crianças por meio de suas histórias; histórias escolares; relações com a classe e a escola; representações e práticas cotidianas que se estabeleceram entre a escola, a família e o aluno. Nada disso tem relevância na compreensão dos seus processos de aprendizagem, uma vez que o conhecimento do aluno que importa é aquele fornecido pelas fases do seu desenvolvimento cognitivo. $\mathrm{O}$ "conhecimento teórico que foi construindo ao longo do tempo", no dizer de uma professora, é que vai "instrumentalizar o professor" na definição das atividades do ensino do aluno (p. 16). O princípio é o de que as leis de funcionamento da mente infantil são aplicáveis a todos os alunos da classe. $\mathrm{O}$ ensino, assim compreendido assume, no entanto, sentido ambíguo e problemático: as práticas pedagógicas devem ser propostas em conformidade com os esquemas lógicos da mente infantil, cuja teoria expressa no documento pretende identificar, descrever e conduzir o trabalho, dirigido ao seu desenvolvimento e à sua adaptação. Todavia, ao se pressupor que todos os alunos reagem dentro de uma gama limitada de possibilidades com o escrito, deixa os professores sem saber o que fazer quando os alunos não se encaixam no esquema preestabelecido. Assim, a apresentação do modelo teórico que deve dirigir o conhecimento do aluno pelo professor (que o documento procura trocar em miúdos para facilitar a compreensão e o uso) acarreta problemas. Toma-se como exemplo o texto "Como se aprende a ler e escrever ou, prontidão, um problema mal colocado" (SÃO PAULO, 2006, p. 133-139), da professora Telma Weisz, já bastante conhecido, cujo original foi substituído, no documento, pelos excertos explicativos de cada etapa esperada de desenvolvimento infantil. A proposta é clara: não se trata de conhecer as crianças, mas de identificá-las. O texto, publicado pela primeira vez em 1987, sofreu, no documento, várias modificações com vistas à leitura rápida e concisa dos estágios de desenvolvimento da escrita nas crianças ${ }^{1}$. Foram suprimidas as três primeiras páginas e as quatro últimas, além de alguns parágrafos do texto original, as notas de rodapé e a bibliografia. Entretanto, é intrigante notar que, na supressão de mais de seis páginas do texto original, que não sabemos se teve o aceite da autora, os fundamentos que sustentam a teó- 
ria psicogenética de aquisição da língua escrita foram eliminados. Ou seja, ao suprimirem o arcabouço teórico que explicava os estágios de escrita ali propostos e que indicava, no texto original, os tipos de problemas de aprendizagem das crianças, as orientações para as intervenções do professor também foram eliminadas.

\section{Rupturas e repetiç̃̃es}

É preciso recordar, entretanto, que o foco do ensino no aluno das camadas populares, partindo de suposto atraso nas suas capacidades de aprendizagem, já faz parte da tradição de estudos que exerceu grande influência no pensamento educacional, desde os anos 1970, no Brasil: as teorias da privação ou marginalidade sociocultural (ref. POPPOVIC, 1972). O lugar hegemônico dessas concepções no pensamento educacional brasileiro foi determinante das maneiras de se pensar a escolarização das crianças e dos adolescentes das camadas populares no país (PATTO, 1997).

A teoria da marginalidade cultural, que, utilizando conceitos piagetianos, principalmente aqueles vinculados ao desenvolvimento da inteligência e ao papel do ambiente, foi alvo de inúmeras críticas nos anos subsequentes. Apesar das críticas e revisões a que foram submetidas, essas teorias, no plano conceitual (PATTO, 1997, entre outros), deixaram marcas profundas no discurso educacional, como se pode constatar. O documento em análise abre possibilidades de interpretação a partir de matrizes conceituais provenientes dessas teorias. No trato de certos temas, na proposição de atividades práticas e de procedimentos didáticos, ambiguidades e contradições abrem brechas às leituras concordantes com a teoria da privação cultural, mas também divergentes e, em alguns momentos, até conflitantes entre si. Uma das marcas dessa tradição no documento é que ele propõe avaliar previamente as capacidades de aprendizagem das crianças para poder planejar o ensino, pressupondo problemas de aprendizagem. Para identificá-los, o recurso são as sondagens baseadas num rol de respostas esperadas, consideradas normais e exemplares. Um dos principais problemas identificados pelos estudos críticos na área (MOYSES; COLLARES, 1997; PATTO, 1997b) é que, como na teoria da privação cultural, o que se analisa é a proximidade ou a distância das aprendizagens 
infantis de certo padrão cognitivo e linguístico considerado a norma, o que conduz à confirmação da existência de atrasos nos níveis de desenvolvimento cognitivo e linguístico, e não permite a compreensão da complexidade das relações que as crianças estabelecem com as atividades escolares nas quais a leitura e a escrita se acham inseridas (suas questões, dúvidas e formas de pensar e de viver a experiência escolar e não escolar). Sabemos, desde Bourdieu (1980), que, nas relações escolares, estão em jogo interesses e implicações sociais específicos que definem e organizam a produção de bens cognitivos em diferentes esferas de produção simbólica e material: as relações de poder entre professores e alunos na sala de aula, as representações que a instituição escolar e o professor produziram de cada aluno e das suas capacidades de aprendizagem. Sabemos que todos esses aspectos interferem no tipo de resposta das crianças às perguntas sobre o sistema escrito.

Também não é possível compreender as formas por meio das quais os alunos estabelecem relações com as práticas de escrita mediante apenas o levantamento de suas hipóteses cognitivas sobre o sistema escrito, como proposto no documento. É preciso considerar as histórias das relações que os alunos estabeleceram com os materiais escritos fora da escola, que sentidos e representações construíram. Desde os trabalhos do antropólogo Jack Goody (1986) sabe-se que, em todas as sociedades onde a burocracia e as relações sociais são mediadas por relações escritas, onde os "papéis" e a "lógica escrita" fazem parte da vida de todos, não há grupos urbanos que não tenham sido submetidos à sua influência. Reafirmando essa tese, estudos têm mostrado que, mesmo entre grupos sociais de baixa escolaridade, as relações que estabelecem com os materiais escritos permitem afirmar que já sejam práticas de leitura e escrita (CERTEAU, 1990; CHARTIER, 1993; SAWAYA, 2000). Na medida em que a avaliação não é o conhecimento das crianças concretas, porém dos seus supostos potenciais de aprendizagem, identificados por intermédio de protocolos prévios, conhecer os alunos, nessa acepção, significa identificar em que estágio se encontra em seu desenvolvimento psicogenético e deduzir, das respostas dadas, as possibilidades de aprendizagem. Assim, a decisão sobre como introduzir as crianças na cultura escrita, apesar das informações contrárias de que se deve introduzir e trabalhar em classe com todos os tipos de textos, passa a ser condicionada pelas avaliações sobre suas capacidades de aprendizagem, o que cria con- 
tradições no próprio documento, prejudicando sua compreensão e seu projeto de formação.

Toma-se como exemplo um dos textos (p. 53-75), escrito sob a forma de uma entrevista com uma pesquisadora renomada, L. Tolchinsky. A proposta de ensino é a de introduzir todas as crianças em atividades programadas cujo objetivo é desenvolver uma série de "condutas linguísticas" - a "alfabetização linguística" (p. 53). O ponto de partida do trabalho pedagógico é um conjunto de procedimentos didáticos assumidos pelo professor, que se expressa tanto na fala, nas conversas, na linguagem oral das crianças em situação comunicativa em sala de aula, quanto na linguagem escrita. O objetivo dessas atividades é desenvolver nas crianças os meios para "ascender a conteúdos culturais", para que elas aprendam a formular questões e a debater sobre o que se passa ao seu redor (p. 55). Recuperando a antiga distinção entre saber ler e saber escrever como atividades separadas, que requerem conhecimentos e recursos distintos (p. 55), o trabalho do professor, nesse texto, é o de recuperar a função da escola como espaço separado dos outros espaços sociais no trato com a linguagem. Ou seja, o ponto de partida para o ensino não é o conhecimento das crianças a partir de critérios prévios do que deveriam saber e do que não sabem, porém a ação propositiva de conteúdos didáticos, a promoção do conhecimento daquilo que se chamou de "aquisição de uma série de condutas linguísticas", que fazem com que a linguagem oral passe a ter outras características, promovidas pela escolarização, nos alfabetizados. Assim, nessa concepção, não se define a priori o que a criança que chega à escola deveria saber.

A proposta parece indicar um caminho diverso do precedente, esboçando projetos e conteúdos de ensino, além de delinear a socialização das crianças por meio do desenvolvimento de projetos culturais (a criação de uma biblioteca a partir do levantamento de temas e interesses), em que o ler e o escrever se colocam como ferramentas de trabalho. Por isso, a proposta é priorizar o "despertar do interesse para ler determinado texto", a partir da pesquisa docente e do levantamento prévio de seus conteúdos e pontos de interesse, identificados pelo professor. A distinção conceitual está no fato de que o que é determinante no processo de aquisição da linguagem escrita não é a capacidade cognitiva prévia das crianças, que passam a ser apenas hipóteses de trabalho, mas a promoção da entrada da criança na cultura escrita, mediante o desenvolvimento de um 
projeto que visa à construção de certa "organização mental", por meio de uma série de "dispositivos intelectuais" promovidos pelo trabalho dirigido para essas finalidades na escola.

Sob a forma de entrevista dirigida por perguntas prévias, o texto não chega, no entanto, a se constituir numa proposta pedagógica de trabalho, como seria de se esperar em um projeto de formação. Recheado de sugestões e propostas de atividades, e seguindo a demanda do entrevistador, pressupõe uma compreensão do trabalho pedagógico a ser desenvolvido que não foi solicitado a explicitar.

A leitura do conjunto dos textos que compõem o material revela, portanto, uma busca em dar respostas à demanda por atividades práticas e a transformar as concepções teóricas em instrumentos de trabalho. No entanto, elas acabaram por se constituir em normatizações, sem que as razões dos procedimentos propostos sejam plenamente explicitadas. É o caso das hipóteses infantis do sistema escrito transformados em testes para sondagem dos níveis conceituais das crianças. Apesar do esforço de apresentação de um conjunto de conceitos e propostas que visa, principalmente, a instruir o professor em serviço na proposição de atividades com a leitura e a escrita em sala de aula, o material não chega a se constituir em um projeto pedagógico de introdução dos alunos na cultura escrita. Uma das razões disso é que o conjunto de definições, princípios, fundamentos e procedimentos que deveria compor a organização pedagógica e curricular de cada unidade de ensino transformou-se em um conjunto de proposições teórico-práticas que buscou responder a demandas que nem sempre são aquelas que a formação para a transformação das práticas dos professores requer. Na medida em que as mudanças nas formas do agir implicam mudanças nos esquemas referenciais dos indivíduos (BLEGER, 1979), é preciso se perguntar se a resistência à mudança dos professores não é resultado não de recusas ou distorções teóricas, mas das contradições e ambiguidades geradas pelo próprio documento. Identificamos, no material, ideias, enraizadas na cultura escolar, de se relacionar e compreender as camadas populares ao lado de propostas pedagógicas que requerem outras concepções de escola e de alunos. 


\section{As teorias psicológicas \\ como fundamentos dos processos de ensino-aprendizagem}

Já não se pode aceitar a ideia de que a transformação da escola, do professor e da formação dos alunos possa se desenvolver somente como resultado da aplicação de novos conceitos de ensino e aprendizagem baseados na construção dos processos internos dos alunos, nem tampouco a reprodução das práticas e dos usos sociais da escrita na escola podem dar conta da introdução dos alunos na cultura escrita.

Estudos têm mostrado (ROCKWELL, 2001) que a pluralidade de usos, a multiplicidade de interpretações e de textos em circulação na escola, dentro e fora da sala de aula, definem os modos de ler, interpretar e escrever que caracterizam a cultura escolar como manifestação plural de formas materiais e simbólicas de leitura e escrita. A escola não é apenas um contexto em que se projetam as ações do ensino, na expectativa de vêlas executadas; bem como a introdução das crianças no universo da "cultura escrita" não é um processo evolutivo e natural, de construção interna dos sujeitos. Nesse sentido, os trabalhos de Lahire (1993) têm evidenciado a existência de uma "forma escolar" da linguagem, que, ao tratar a língua como objeto de conhecimento, demanda dos alunos a "conversão a outra lógica de relação com a linguagem", distinta dos seus usos comuns. Contudo, não basta a exposição dos indivíduos às práticas e aos usos sociais da escrita e da leitura para que as adquiram. Essa outra forma de racionalidade no trato com a linguagem, distinta da lógica que caracteriza as culturas orais, demanda um trabalho escolar de "inculcação". Ou seja, trata-se, no dizer desse autor, da conversão das relações com a linguagem que transformam as relações orais (aprender vendo fazer, imitando gestos e comportamentos) em relações de objetivação, decorrentes do processo de "escrituração das práticas sociais". Cabe, portanto, à escola, mediante um processo de imposição, de normatização e codificação, a conversão das crianças a modos de regulação e de aprendizagens determinadas.

É preciso, portanto, não esquecer os inúmeros procedimentos que, historicamente, têm constituído as práticas escolares, sob o risco de "jogar a criança com a água do banho", ao chamar todas elas de práticas tradicionais e tentar fundar novas práticas, baseando-se apenas na crença de que os usos e as práticas sociais da escrita são destituídos de um traba- 
lho de "domesticação do pensamento": formas de construção do texto que implicam a classificação e a organização das ideias, da construção da sua narração, que não são processos naturais nem universais, mas demandam um processo de socialização específico. Nesse sentido, os professores não são apenas orientadores, mas aqueles que devem ajudar seus alunos a "domesticarem seus pensamentos" (LAHIRE, 2008, p. 151). Portanto, na escola, os professores precisam ser conduzidos a reassumir seu papel no ensino e na condução da aprendizagem, na participação ativa na constituição dos processos que não se restringem aos aspectos cognitivos. A definição do trabalho pedagógico como de promoção do desenvolvimento do pensamento, da capacidade de aprendizagem do aluno, da resolução de problemas e do uso de habilidades, objetivos que, aliás, já estavam presentes nos precursores da Escola Nova, não pode ser decorrência direta da proposição de atividades. A insuficiência da proposta de atividades na condução do trabalho do educador não passa, no entanto, inadvertida entre os vários textos que compõem o documento. Toda vez que se menciona a necessidade de intervenção psicopedagógica do professor - como no caso de alunos que, apesar das atividades propostas, não escrevem -, é o especialista que é invocado a intervir. Assim é que a própria proposta de formação previu contar com um aluno dos cursos de Pedagogia nos HTPCs, além do coordenador pedagógico. Além do mais, a proposta exige uma formação docente que não se propõe oferecer. A retomada, no documento, da divisão do trabalho docente entre aquele que pensa e aquele que executa não é um equívoco ou um aligeiramento nas proposições do documento; é o reflexo do novo perfil do professor e do pedagogo que vêm sendo gerados com a criação dos diferentes sistemas de formação, os primeiros, nos institutos superiores de educação - ISE -, e os segundos, nas faculdades de Pedagogia (FREITAS, 2002). Além do mais, a divisão das tarefas entre o educador e o pedagogo que vem se delineando no sistema de formação é facilitada pelo fato de que os próprios conteúdos do ensino não ocupam lugar importante. Ao professor cabe executar as atividades propostas, pois elas serão analisadas e interpretadas pelo pedagogo-especialista. Não por acaso, o modelo didático proposto assume a conotação própria de um discurso sobre as regras a se adotar para desenvolver a ação educativa com vista ao desenvolvimento cognitivo. A ação pedagógica, como o próprio documento busca esclarecer, é a interação de natureza conceitual entre "aluno (o objeto do conhecimen- 
to), a língua e o ensino [...], concebido como a prática educacional que organiza a mediação entre sujeito e objeto de conhecimento" (p. 33).

A prática educativa, nessa acepção, não é um processo intersubjetivo, psicossocial, sociocultural, no qual professor e aluno se acham intimamente implicados com suas histórias, percepções e práticas cotidianas. Sabemos que a ação pedagógica não é uma regra a ser aplicada, mas se desenvolve a partir da historicidade dos gestos, da memória das inter-relações pessoais e em meio a práticas escolares que constituem a escola como organização social e cultural. 


\section{Referências}

BLEGER, J. Temas em Psicologia Entrevista e Grupos. São Paulo: Martins Fontes, 1979. BOURDIEU, P. Le sens pratique. Paris: Minuit, 1980.

BRASIL, Ministério da Educação e do Desporto. Secretaria de Educação Fundamental. Parâmetros Curriculares Nacionais, Introdução. Brasília: MEC, 1997. v. 1.

BROCK, C.; SCHWARTZMAN, S. (Orgs.). Os desafios da educação no Brasil. Rio de Janeiro: Nova Fronteira, 2005.

CERTEAU, M. A escrita da história. Rio de Janeiro: Forense-Universitária, 1982.

CERTEAU, M. L'invention du quotidien. 1. Arts de faire. Paris: Gallimard, 1990.

CHARTIER, R. Du livre au lire. Pratiques de la lecture. Marsella: Payot et Rivages, 1993.

CHARTIER, R. Entrevistas. In: Cultura escrita, literatura e historia: conversaciones con Roger Chartier. Mexico: Fondo de Cultura Economica, 1999.

CARVALHO, J. S. O discurso pedagógico das Diretrizes Curriculares Nacionais: competência crítica e interdisciplinaridade. Cadernos de Pesquisa, n. 112, p. 155-165, março 2001. DUARTE, N. Vygostski e o "aprender a aprender". 2 ed. Campinas: Autores Associados, 2001.

FREITAS, M. H. Formação de professores no Brasil: 10 anos de embate entre projetos de formação. Educ. Soc., Campinas, v. 23, n. 80, p. 136-167, set. 2002.

GONDRA, J. G. Modificar com brandura e previnir com cautela. Racionalidade médica e higienização da infancia. In: M.C. Freitas e M. Kulmann Jr. Os intelectuais na história da infância. São Paulo: Cortez, 2002.

GOODY, J. The logic of writing and the organization of society. Cambridge: Cambridge University Press, 1986.

LAHIRE, B. Culture écrite et inégalités scolaires. Sociologie de l'échec scolaire a l'école primaire. Lyon: Presses Universitaires de Lyon, 1993.

LAHIRE, B. La raison scolaire. Ecole et pratiques d'écriture, entre savoir et pouvoir. Presse Universitaires de Rennes, 2008.

MELLO, G. N. Magistério de primeiro grau: da competência técnica ao compromisso político. São Paulo: Cortez, 1988.

MELLO, G. N. Educação escolar brasileira: o que trouxemos do século XX. Porto Alegre: Artmed, 2004.

MOYSES, M. A.; COLLARES, C. Inteligência abstraída, crianças silenciadas: as avaliações de inteligência. Psicologia USP, São Paulo, v. 8, n. 1, p. 63-89, 1997.

PATTO, M. H. A produção do fracasso escolar. 2 ed. São Paulo: Casa do Psicólogo, 1997.

PATTO, M. H. Para uma crítica da razão psicométrica. Psicologia USP, São Paulo, v. 8, n. 1, p. 47- 62, 1997b.

POPPOVIC, A.M. Atitudes e cognição do marginalizado cultural. Revista Brasileira de Estudos Pedagógicos, v. 26, n. 57, p. 244-245, 1972.

ROCKWELL, E. La lectura como practica cultural: conceptos para el estudio de los libros escolares. Educaçao e Pesquisa, Sao Paulo, v. 27, n. 1, p. 11-26, jan.-jun 2001.

SÃO PAULO, Secretaria de Estado da Educação. Documento Preliminar n. 1. 1986.

SÃO PAULO, Secretaria Municipal de Educação. Programa Ler e Escrever Prioridade na Escola, Toda Força ao $1^{\circ}$ ano Guia de Estudos para o Horário Coletivo de Trabalho, DOT, abril 2006. 
SÃO PAULO, Secretaria Municipal de Educação. Programa Ler e Escrever Prioridade na Escola, Toda Força ao $1^{\circ}$ ano. Orientações para o planejamento e avaliação do trabalho com o $1^{\mathrm{a}}$. Ano do Ensino Fundamental - Ciclo I. 2006a.

SAVIANI, D. História das idéias pedagógicas no Brasil. Campinas: Autores Associados, 2007. SAWAYA, S. M. Alfabetização e fracasso escolar: problematizando alguns pressupostos da concepção construtivista. Educação e Pesquisa, São Paulo, v. 26, n. 1, p. 67-81, jan.-jun. 2000 .

SCHWARCZ, L. M. O espetáculo das raças, cientistas, instituições e questão racial no Brasil, 18701930. São Paulo: Companhia das Letras, 2001.

SOUZA, D. T. R. Formação continuada de professores e fracasso escolar: problematizando o argumento da incompetência. Educação e Pesquisa. v. 32, n. 3, São Paulo set.-dez. 2006.

SILVA, T. T. da. Identidades terminais. Rio de Janeiro: Vozes, 1996.

VASCONCELOS, M. S. A difusão das idéias de Piaget no Brasil. São Paulo: Casa do Psicólogo, 1996.

\section{Nota}

1 Visando à sua rápida consulta durante a avaliação da sondagem, como pode ser comprovado em outro documento (SÃO PAULO, 2006b, p. 36), um box à margem da página lembra o professor de recorrer a "essas etapas" para analisar o que os alunos produziram na sondagem.

Recebido: $23 / 11 / 2010$ 